\title{
ANÁLISIS BIBLIOTECOLÓGICO DE LOS NOTICIEROS TELEVISIVOS MEXICANOS EN LA WEB
}

\section{Silvano Soto-Hernández y Catalina Naumis-Peña}

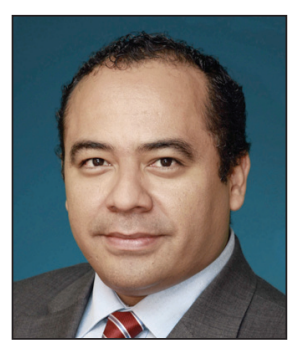

Silvano Soto-Hernández es doctorando en bibliotecología y estudios de la información en el Instituto de Investigaciones Bibliotecológicas y de la Información de la Universidad Nacional Autónoma de México (UNAM), licenciado en ciencias de la comunicación por la Universidad del Valle de México y maestro en bibliotecología y estudios de la información por la UNAM. Ha sido reportero de televisión, coordinador de investigación audiovisual y de producción de programas noticiosos y de entretenimiento en la cadena internacional Grupo Televisa.

http://orcid.org/0000-0002-8299-1519

silvano.doctorado@gmail.com

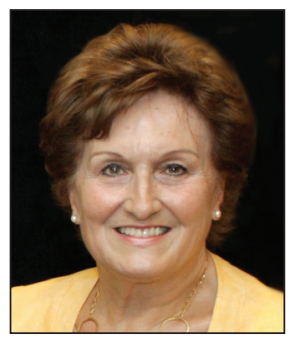

Catalina Naumis-Peña es investigadora del Instituto de Investigaciones Bibliotecológicas y de la Información de la Universidad Nacional Autónoma de México (UNAM). Es doctora en ciencias de la información por la Universidad Complutense de Madrid (2002), maestra en bibliotecología por la UNAM (1995) y licenciada en bibliotecología por la UNAM (1983). Es miembro del Sistema Nacional de Investigadores. Como docente, imparte el seminario de lenguajes documentales: un análisis de contenido, en el nivel maestría y es tutora de tesis para maestría y doctorado.

http://orcid.org/0000-0003-3152-3958

naumis@unam.mx

Universidad Nacional Autónoma de México, Delegación Coyoacán Torre Humanidades II, piso 12. Ciudad Universitaria, México, D.F.

\section{Resumen}

La televisión es vehículo indiscutible para socializar el relato periodístico del acontecer humano. La evolución de la documentación periodística, así como la necesidad de dar respuesta a la organización de los contenidos generados en las videotecas y los archivos televisivos, en particular el estudio del noticiero, ha creado nuevos ámbitos y nichos de oportunidades para los profesionales de la bibliotecología y la información. Se presenta la investigación que se realiza en México en torno al análisis y la representación de contenido de los noticieros televisivos en la Web. El tratamiento documental del noticiero es crucial para fortalecer la calidad de la representación del contenido y asegurar la pertinencia del análisis del discurso para su organización, acceso y preservación. La visibilidad de los contenidos de las televisiones en la Web podría verse reducida debido a las carencias en la descripción del contenido mediante metadatos.

\section{Palabras clave}

Documentación periodística, Documentación audiovisual, Documentación en televisión, Periodismo televisivo, Organización documental, Noticieros, Telenoticias, Telediarios, Representación de contenido, Televisión, Web, Indización, Metadatos.

\section{Title: Library science analysis of Mexican television news on the web}

\begin{abstract}
Television is unquestionably a vehicle that socializes the journalistic tale of the human experience. The evolution of journalistic documentation and the need to respond to the organization of content generated in video collections and television archives, in particular news broadcasts, have created new areas and niches of opportunity for library and information science professionals. The research that is being carried out in Mexico on the analysis of news broadcasts and content representation on the web is presented. The documentary news treatment is crucial to strengthen the quality of content representation and ensure the relevance of discourse analysis for its organization, accessibility and preservation. The visibility of television news on the Web could be lessened due to deficiencies in metadata description.
\end{abstract}

\section{Keywords}

News librarianship, Audiovisual documentation, TV documentation, TV Journalism, News, Documentary organization, Content representation, Web, Television, Metadata, Indexing.

Soto-Hernández, Silvano; Naumis-Peña, Catalina (2014). "Análisis bibliotecológico de los noticieros televisivos mexicanos en la Web". El profesional de la información, enero-febrero, v. 23, n. 1, pp. 80-86. 


\section{Aproximación a la televisión mexicana}

La televisión es una industria cultural generadora y transmisora de un discurso o conjunto de representaciones cognitivas con formato, estructura, contenido, tono e intencionalidad diversa (Sabido, 2002). En cada país, el origen y evolución de la televisión ha motivado la formación de modelos con marcos jurídicos y operativos, funciones y normas tecnológicas diferentes (Smith, 1995).

En el caso mexicano, la industria de la televisión derivó de la estadounidense en la mayoría de sus rasgos, tanto por la cercanía geográfica, como por la influencia de la política en diversos órdenes y las relaciones que hay entre los dos países (Lasswell, 1948, pp. 37-51).

La televisión en México comenzó a operar en 1950, pero no fue hasta 1960 cuando se promulgó la Ley Federal de Radio y Televisión en la que se establecen las bases jurídicas para la regulación y operación del medio bajo dos modalidades: la concesión y el permiso.

Las estaciones comerciales requieren concesión. Las estaciones oficiales, culturales, de experimentación o las que establezcan las entidades y organismos públicos para el cumplimiento de sus fines y servicios, sólo necesitan permiso (Ley Federal de Radio y Televisión, 2012).

En ambos casos, las funciones que se espera que la televisión desempeñe incluyen, de acuerdo con la ley:

a) afirmar el respeto a los principios de la moral social, la dignidad humana y los vínculos familiares;

b) evitar influencias nocivas o perturbadoras al desarrollo armónico de la niñez y la juventud;

c) contribuir a elevar el nivel cultural de la población y a conservar las características nacionales, las costumbres del país y sus tradiciones, la propiedad del idioma y a exaltar los valores de la nacionalidad mexicana;

d) fortalecer las convicciones democráticas, la unidad nacional y la amistad y cooperación internacionales.
La tabla 1 presenta una síntesis del estado actual que guardan las cuatro televisiones con mayor cobertura y penetración en México considerando atributos como la titularidad o régimen jurídico, los canales de transmisión, el ámbito geográfico que alcanzan, los canales de difusión, la orientación temática y la estructura organizacional.

Las televisiones mexicanas a las que refiere la tabla 1 cuentan con equipos de producción y redacciones integradas. Desde la más longeva hasta la más joven, han adaptado los géneros televisivos desarrollados en Estados Unidos de América principalmente y, desde el año 2000, optaron por la introducción del reality show que tuviera auge en Europa. Mediante estos contenidos y su programación estratégica se persigue cautivar la atención del público televidente (Soto, 2011, pp. 223-248).

\section{Desde 2010 las televisiones mexicanas han ampliado la difusión de los noticie- ros en internet, abriendo nuevas posibi- lidades para acceder a ellos}

En cuanto a la participación de audiencia, de acuerdo con la empresa de medición en televisión Nielsen-lbope, para junio de 2013, de cada 100 personas que tienen encendido el televisor en las 28 ciudades medidas en el estudio Establishment survey (basándose en 23 mil encuestas), 43 ve algún canal de televisión abierta de Televisa.

Aunque podría señalarse que la mayoría de los contenidos son elaborados simplemente para que la audiencia los reciba de manera pasiva, indirecta y con escasa participación (Jara-Elías; Garnica-Andrade, 2007), también es cierto que las nuevas tecnologías de información y comunicación en internet facilitan la interacción del público. Así se aprecia a través de expresiones del comportamiento del televidente/ internauta como son la manifestación del interés por determinadas temáticas y personalidades, la jerarquización de la

Tabla 1. Caracterización de las televisiones mexicanas (cadenas o canales)

IPN: Instituto Politécnico Nacional. Conaculta: Consejo Nacional para la Cultura y las Artes

Ambas son entidades que dependen del Gobierno de la República Mexicana o de alguna de sus secretarías.

\begin{tabular}{|c|c|c|c|c|}
\hline & Televisa & TV Azteca & IPN & $\begin{array}{c}\text { Conaculta } \\
\text { Televisión Metropolitana }\end{array}$ \\
\hline Titularidad & Concesión & Concesión & Permiso & Permiso \\
\hline Inicio operación & 1950 & 1993 & 1959 & 1996 \\
\hline Canales & $2,4,5$ y 9 & 7 y 13 & 11 & 22 \\
\hline Ámbito geográfico & Nacional (excepto el 4) & Nacional & Nacional & Nacional \\
\hline Canales de difusión & $\begin{array}{l}\text { TV abierta } \\
\text { TV de pago/cable } \\
\text { TV de pago/satélite } \\
\text { TV por internet } \\
\text { TV por app }\end{array}$ & $\begin{array}{l}\text { TV abierta } \\
\text { TV de pago/cable } \\
\text { TV de pago/satélite } \\
\text { TV por internet } \\
\text { TV por app }\end{array}$ & $\begin{array}{l}\text { TV abierta } \\
\text { TV de pago/cable } \\
\text { TV de pago/satélite } \\
\text { TV por internet } \\
\text { TV por app }\end{array}$ & $\begin{array}{l}\text { TV abierta } \\
\text { TV de pago/cable } \\
\text { TV de pago/satélite } \\
\text { TV por internet }\end{array}$ \\
\hline Orientación & $\begin{array}{l}\text { Generalista (excepto el } \\
4 \text { dedicado a programas } \\
\text { periodísticos) }\end{array}$ & Generalista & $\begin{array}{l}\text { Generalista } \\
\text { (con énfasis cultural) }\end{array}$ & $\begin{array}{l}\text { Temática } \\
\text { (cultural) }\end{array}$ \\
\hline Estructura & $\begin{array}{l}\text { Redacción y producción in- } \\
\text { tegrada con compra y venta } \\
\text { de contenidos }\end{array}$ & $\begin{array}{l}\text { Redacción y producción } \\
\text { integrada con compra y venta } \\
\text { de contenidos }\end{array}$ & $\begin{array}{l}\text { Redacción y producción } \\
\text { integrada con compra y } \\
\text { venta de contenidos }\end{array}$ & $\begin{array}{l}\text { Redacción y producción } \\
\text { integrada con compra y } \\
\text { venta de contenidos }\end{array}$ \\
\hline
\end{tabular}


información estableciendo el orden/secuencia de visionado; o la elección del curso que llevará el relato y destino de los personajes en los contenidos de estructura dramática.

Como objeto de estudio amplio, la televisión ha sido abordada desde diversas perspectivas de investigación especializada. Desde su aparición, el medio, su proceso de producción, su discurso y sus efectos en la audiencia han sido analizados a través de variedad de enfoques (Curran, 1990). El propósito de este artículo no incluye hacer un recuento sobre este aspecto en particular. No obstante, queda como referencia para el caso mexicano la existencia de bibliografía sobre el estudio de la televisión en el país y las tendencias que han guiado a la investigación (Sánchez-Ruiz, 1989).

\section{Televisión e investigación bibliotecológica y de la información}

La Organización de las Naciones Unidas (ONU) aprobó en 2005 la conmemoración del Día Mundial del Patrimonio Audiovisual, como mecanismo para generar conciencia acerca de la necesidad de tomar medidas urgentes y reconocer la importancia de los documentos audiovisuales como objetos que confluyen en la conformación de la identidad nacional.

Entonces quedó a la vista de la sociedad la existencia de registros documentales televisivos que debían identificarse y organizar para analizar su contenido, comprender su valor y los riesgos que implica el carácter efímero de los soportes materiales (González-Gonzalo, 2001).

Esta conceptualización de la televisión impulsó el desarrollo de proyectos de investigación, facilitando la conformación de núcleos de estudio de los documentos audiovisuales en varios entornos disciplinarios: la library science (EUA), la documentación audiovisual (España), la documentation audiovisuelle (Francia), la documentazione audiovisiva (Italia), la audiovisuellen dokumentation (Alemania) y, por supuesto, Australia donde hay un importante movimiento sobre los archivos audiovisuales (Edmonson, 2008).

En España la investigación sobre este tema ha sido especialmente prolífica (Caldera-Serrano; Arranz-Escacha, 2012), y podemos identificar líneas de trabajo científico acerca de pautas generales, políticas de actuación y gestión, y tecnología en el contexto de la documentación audiovisual (Caldera-Serrano; Benítez-Jaramillo, 2005).

En México se han realizado contribuciones desde la perspectiva de la bibliotecología y los estudios de la información entre las que destacan la creación de un tesauro diseñado para su aplicación en videotecas educativas (Naumis-Peña, 2003) y el desarrollo de metodologías para el tratamiento documental del video (Soto-Hernández, 2009).

En lo que concierne al estudio de la producción del periodismo televisivo, en primer lugar se ha identificado que el género no representa el mayor porcentaje de tiempo en la programación de las cadenas mexicanas, y se encuentra por detrás de las telenovelas, los deportivos y las películas.

No obstante, sin descartar el interés por otros géneros, el noticiero reviste relevancia ya que es una obra intelectual que mantiene a la sociedad al tanto de lo que ocurre en el contexto, a través del relato de los acontecimientos de inte- rés público en diversidad de temáticas.

En México, la posibilidad para el acceso al noticiero como documento de investigación se reduce notablemente a las capacidades del investigador para guardar copia de las transmisiones de televisión. Esto se debe a que la producción y difusión de los noticieros no se ve afectada por el depósito legal que incluye a los materiales bibliográficos y documentales editados y producidos en el país, considerándolos parte del patrimonio cultural de la nación (Decreto Presidencial del 8 de julio de 1991).

A pesar de estas condiciones, desde 2010 las televisiones mexicanas han ampliado la difusión de los noticieros en internet, abriendo nuevas posibilidades para acceder a ellos, lo que plantea nuevas exigencias para organizar y representar su contenido. De ahí que para la investigación bibliotecológica y de la información resulte de interés tomar el noticiero como un documento objeto de estudio.

El noticiero es un tipo de discurso periodístico en el que confluye el uso del lenguaje en sus manifestaciones oral, escrita, audiovisual y documental

\section{Investigación sobre noticieros televisivos mexicanos en internet}

Los estudios realizados desde las ciencias sociales y humanidades plantean constantemente la necesidad del análisis del discurso televisivo. Existe una cantidad importante de trabajos de investigación sobre el entretenimiento, el análisis político, la indagación histórica y el quehacer historiográfico que requieren consultar los programas periodísticos como fuente documental válida de información (ChacónGutiérrez, 1999).

En cuanto a la docencia y la investigación bibliotecológica y de la información en México, se realizan en la actualidad trabajos para discernir y precisar el concepto, estructura y funciones del noticiero televisivo. Asimismo se busca generar la reflexión teórica sobre el análisis y representación documental del género.

El noticiero (llamado también telediario o noticiario) es un tipo de discurso periodístico en el cual confluye el uso del lenguaje en sus manifestaciones oral, escrita y audiovisual; así como una más que es la documental pues queda evidencia en un soporte.

Al mismo tiempo, fomenta la interacción de las personas en el marco de un contexto, y es vehículo facilitador de la comunicación social de principios, valores y creencias, generando representaciones cognitivas como son los códigos, rasgos y significados (Condor; Antaki, 2000).

Para abordar el tema de investigación, se propuso como objetivo analizar los atributos que caracterizan la representación de contenido de los noticieros televisivos mexicanos en la web, con la finalidad de identificar las oportunidades para mejorar su organización, publicación y acceso tanto a 
los usuarios en general como a los que realizan actividades de investigación especializada. Se analizó una variedad de casos de noticieros televisivos mexicanos con exposición en internet (tabla 2).

Tras efectuar el seguimiento y el análisis de los noticieros estelares o principales de las cadenas referidas en la tabla 2 , se encontró que cada emisión podía ser considerada como una macroestructura producto de tres niveles de articulación de signos (Gil-Leiva, 2008, pp. 21-23).

La primera articulación se da en el plano de las microestructuras donde se enlazan los textos leídos por el presentador del noticiero con otras unidades sintagmáticas como son las notas periodísticas, reportajes, crónicas, entrevistas, opiniones, semblanzas, resúmenes, avances previos al corte.

En una segunda articulación, estas primeras microestructuras están compuestas por elementos menos complejos o proposiciones, donde texto, sonido e imágenes (fijas o en movimiento) quedan yuxtapuestos después de los procesos de montaje, edición y postproducción audiovisual.

Cada noticiero guarda un determinado nivel de coherencia y congruencia entre las proposiciones, las microestructuras y las macroestructuras. Esto permite que el discurso periodístico del noticiero pueda comunicarse con significado, sentido y dirección hacia el receptor, permitiéndole generar a su vez una representación cognitiva (figura 1).

En las televisiones mexicanas, el profesional de la información necesita comprender cómo se encuentran articulados los noticieros considerados como discursos, para posteriormente llevar a cabo el tratamiento y organización documental.

Por un lado debe entrenarse para lograr los objetivos de carácter sincrónico, más apegados a lo que tradicionalmente se reconoce como tareas y productos derivados de esta forma de procesamiento del documento audiovisual: visionado, calificación (también llamado minutado), resumen, representación semántica y asignación de palabras clave (no necesariamente términos descriptores normalizados o autoridades). Son sincrónicos porque se realizan cuando se está produciendo el noticiero, que es la etapa de mayor actividad de su ciclo de vida.

Los materiales que llegan a la videoteca o archivo suelen estar sujetos a los procesos técnicos de ingreso, identificación, análisis, descripción (física/técnica y temática), y almacenamiento. De otra forma fácilmente podrían presentarse problemas que van desde la acumulación de documentos sin control, a la imposibilidad de atender la línea de producción para quienes editan las microestructuras que conformarán el noticiero y, en el peor de los casos, el extravío temporal o definitivo del material.

Por otro lado se encuentran los objetivos asíncronos; es decir, los análisis posteriores tanto de los materiales audiovisuales en su estado original de cámara (antes de ser seleccionados por el reportero, el editor, el realizador, el productor e incluso el conductor), como del resultado final.

Si en el curso del proceso sincrónico es necesaria una descripción física/técnica y temática somera del objeto audiovisual, una vez que el noticiero ha sido transmitido debiera

Tabla 2. Transmisión de noticieros en México según canal de difusión

\begin{tabular}{|l|c|c|c|}
\hline \multicolumn{1}{|c|}{ Canal de televisión } & TV abierta & TV de pago & TV internet \\
\hline Aprende- Televisión educativa & & $\mathrm{X}$ & $\mathrm{X}$ \\
\hline CNN México & & $\mathrm{X}$ & $\mathrm{X}$ \\
\hline Cadenatres & & $\mathrm{X}$ & $\mathrm{X}$ \\
\hline Canal once & $\mathrm{X}$ & & $\mathrm{X}$ \\
\hline Efekto TV & & $\mathrm{X}$ & $\mathrm{X}$ \\
\hline ExcélsiorTV $\left.{ }^{*}\right)$ & & & $\mathrm{X}$ \\
\hline Foro TV/Televisa $\left(^{*}\right)$ & $\mathrm{X}$ & & $\mathrm{X}$ \\
\hline Fuerza informativa azteca & $\mathrm{X}$ & & $\mathrm{X}$ \\
\hline Milenio noticias $\left(^{*}\right)$ & & $\mathrm{X}$ & $\mathrm{X}$ \\
\hline MVS noticias & & $\mathrm{X}$ & $\mathrm{X}$ \\
\hline Noticieros Televisa & $\mathrm{X}$ & & $\mathrm{X}$ \\
\hline Proyecto 40 & & $\mathrm{X}$ & $\mathrm{X}$ \\
\hline Telefórmula & & $\mathrm{X}$ & $\mathrm{X}$ \\
\hline Televisión metropolitana Canal 22 & $\mathrm{X}$ & $\mathrm{X}$ & $\mathrm{X}$ \\
\hline TV UNAM & & & \\
\hline
\end{tabular}

Nota: Se tomaron en consideración las televisiones que producen y transmiten por lo menos un noticiero al día. Los casos señalados con $\left({ }^{*}\right)$ son canales con temática periodística, transmitiendo las 24 horas. 
existir la posibilidad de realizar un análisis más detallado:

- para poner a disposición de la cadena y sus autoridades los elementos suficientes para llevar a cabo la valoración, selección y preservación a corto, medio y largo plazo;

- para facilitar la consulta con fines de investigación social (cuando el marco legal y las políticas de las cadenas lo permiten, aspecto que presenta variaciones en cada país);

- para consumo interno de la propia organización, e incluso la comercialización.

Al analizar los noticieros o fragmentos de ellos (en vivo o bajo demanda) de las cadenas mexicanas en internet, se vio que en la mayoría de los casos carecen de metadatos sobre el contenido como son:

- palabras clave o términos descriptores;

- nombres propios de personas o lugares;

- temas relacionados;

- ofrecimiento del guión o escaleta del noticiero completo o el fragmento del que se trate.

La tabla 3 muestra la situación. La correcta representación del contenido de los noticieros es un aspecto especialmente sensible ya que de ello depende el conocimiento que se tiene de las videotecas y archivos de las cadenas, consideradas como organizaciones insertadas en la sociedad. una macroestructura discursiva cifrada en un código que amalgama el lenguaje textual con el audiovisual. Es una representación cognitiva de un conjunto de acontecimientos relevantes y de interés general presentada a una audiencia.

El producto final, el noticiero transmitido, es la representación audiovisual del guión, casi siempre codificado en texto, cuya organización interna implica la jerarquización de microestructuras discursivas (bloques temáticos, noticias, reportajes, entrevistas, etc.), y las proposiciones que conforman cada línea de texto del presentador o del reportero que hace la lectura del guión de cada nota informativa (Bock, 2011). Esta secuencia de generación de representaciones discursivas en el flujo de la producción audiovisual en los noticieros se observa en la figura 2.

Una vez que ha sido transmitido, el noticiero se convierte en un objeto documental. Aquí se genera uno de los ele-
Existen dos niveles de descripción del noticiero:

- su producción audiovisual;

- su contenido, con elementos tales como resumen, términos de indexación o palabras clave, o la ficha de catálogo detallada.

Un noticiero es una obra intelectual audiovisual que comprende diversas actividades, que varían de una cadena a otra (tabla 3), y que en los años recientes ha alcanzado mayores niveles de sofisticación (Cummins; Chambers, 2011). Puede ser considerado como
Tabla 3. Noticieros de México según metadatos que representan el contenido de la emisión o de sus fragmentos

\begin{tabular}{|l|c|c|c|c|c|c|c|c|c|c|c|c|}
\hline \multicolumn{1}{|c|}{ Cadena } & A & B & C & D & E & F & G & H & I & J & K & L \\
\hline Aprende- Televisión educativa & $\mathrm{X}$ & $\mathrm{X}$ & $\mathrm{X}$ & $\mathrm{X}$ & & & & & & & & $\mathrm{X}$ \\
\hline CNN México & $\mathrm{X}$ & $\mathrm{X}$ & $\mathrm{X}$ & $\mathrm{X}$ & $\mathrm{X}$ & & & $\mathrm{X}$ & $\mathrm{X}$ & & & $\mathrm{X}$ \\
\hline Cadenatres & $\mathrm{X}$ & $\mathrm{X}$ & $\mathrm{X}$ & $\mathrm{X}$ & $\mathrm{X}$ & & & & $\mathrm{X}$ & & & $\mathrm{X}$ \\
\hline Canal once & $\mathrm{X}$ & $\mathrm{X}$ & $\mathrm{X}$ & $\mathrm{X}$ & & & & & $\mathrm{X}$ & $\mathrm{X}$ & & \\
\hline Efekto TV & $\mathrm{X}$ & $\mathrm{X}$ & $\mathrm{X}$ & $\mathrm{X}$ & $\mathrm{X}$ & & & & $\mathrm{X}$ & $\mathrm{X}$ & & $\mathrm{X}$ \\
\hline Excélsior TV $\left(^{*}\right)$ & $\mathrm{X}$ & $\mathrm{X}$ & $\mathrm{X}$ & $\mathrm{X}$ & & & & & $\mathrm{X}$ & & & \\
\hline Foro TV/Televisa $\left(^{*}\right)$ & $\mathrm{X}$ & $\mathrm{X}$ & $\mathrm{X}$ & $\mathrm{X}$ & $\mathrm{X}$ & & & & $\mathrm{X}$ & $\mathrm{X}$ & & $\mathrm{X}$ \\
\hline Fuerza informativa azteca & $\mathrm{X}$ & $\mathrm{X}$ & $\mathrm{X}$ & $\mathrm{X}$ & & & & & $\mathrm{X}$ & $\mathrm{X}$ & & $\mathrm{X}$ \\
\hline Milenio noticias $\left(^{*}\right)$ & $\mathrm{X}$ & $\mathrm{X}$ & $\mathrm{X}$ & $\mathrm{X}$ & $\mathrm{X}$ & & & & $\mathrm{X}$ & $\mathrm{X}$ & & $\mathrm{X}$ \\
\hline MVS noticias & $\mathrm{X}$ & $\mathrm{X}$ & $\mathrm{X}$ & $\mathrm{X}$ & $\mathrm{X}$ & & & & $\mathrm{X}$ & & & $\mathrm{X}$ \\
\hline Noticieros Televisa & $\mathrm{X}$ & $\mathrm{X}$ & $\mathrm{X}$ & $\mathrm{X}$ & $\mathrm{X}$ & & & & $\mathrm{X}$ & $\mathrm{X}$ & & $\mathrm{X}$ \\
\hline Proyecto 40 & $\mathrm{X}$ & $\mathrm{X}$ & $\mathrm{X}$ & $\mathrm{X}$ & $\mathrm{X}$ & & & & $\mathrm{X}$ & $\mathrm{X}$ & & $\mathrm{X}$ \\
\hline Telefórmula & $\mathrm{X}$ & $\mathrm{X}$ & $\mathrm{X}$ & $\mathrm{X}$ & $\mathrm{X}$ & & & & & $\mathrm{X}$ & & $\mathrm{X}$ \\
\hline Televisión metropolitana Canal 22 & $\mathrm{X}$ & $\mathrm{X}$ & $\mathrm{X}$ & $\mathrm{X}$ & $\mathrm{X}$ & & & & $\mathrm{X}$ & $\mathrm{X}$ & & $\mathrm{X}$ \\
\hline TV UNAM & $\mathrm{X}$ & $\mathrm{X}$ & $\mathrm{X}$ & $\mathrm{X}$ & & & & & $\mathrm{X}$ & & & \\
\hline
\end{tabular}

A: Título del noticiero/noticia; B: Fecha del noticiero/noticia; C: Horario de transmisión/fecha y hora de posteo; D: Conductores; E: Síntesis del noticiero/nota; F: Palabras clave o términos descriptores; G: Nombres propios de personas o lugares; H: Temas relacionados; I: Extensión de contenido en redes sociales; J: Ofrece el noticiero en versión completa en vivo o bajo demanda; K: Ofrece guión o escaleta del noticiero completo; L: Ofrece los fragmentos del noticiero bajo demanda. 
mentos más importantes de toda la cadena documental, pues se contribuye al establecimiento del patrón de datos (o metadatos) que facilitarán en gran medida la valoración, selección y preservación.

\section{La visibilidad de los contenidos de las te- levisiones mexicanas en la Web podría verse reducida debido a las carencias en la representación del contenido}

Se trata de una etapa en la que es posible contrastar la fidelidad con la que los hechos o acontecimientos reseñables fueron representados en el guión (paso 1) y la fidelidad con la que el guión propuesto originalmente por los periodistas, reporteros y redactores, se materializó a través de la edición de imágenes y sonidos, en un discurso coherente y consistente (paso 2). Es decir, es en este punto en el que se propicia la mayor factibilidad para verificar el grado de calidad que se ha impreso al análisis y representación de contenido. Por ejemplo, se pueden presentar algunos de los siguientes supuestos:

- el noticiero transmitido finalmente presenta una secuencia u orden de presentación de sus microestructuras (noticias, reportajes, textos comentados por el conductor, etc.) distinto del guión original;

- las microestructuras presentan variaciones desde leves a significativas respecto al guión original;

- las microestructuras fueron editadas con imágenes fijas o en movimiento que no guardan correspondencia con el texto escrito por el reportero o por el redactor, generando incongruencia en el producto audiovisual final (por no mencionar los efectos en la audiencia tanto en el plano semántico como en el cognitivo de la comprensión periodística de los acontecimientos reseñados).

En este último aspecto resulta crucial contar con un proceso de tratamiento documental del noticiero para fortalecer la calidad de la representación del contenido (tanto en el flujo síncrono como asíncrono) para asegurar la pertinencia del análisis del discurso para su organización, acceso y eventual posterior preservación.

\section{Consideraciones finales}

Entre los productos que genera la televisión, el noticiero tiene un papel relevante, y desde todas las disciplinas que lo estudian existe un abordaje especial para el mismo. En este marco, la disciplina de la bibliotecología e información no es la excepción porque contempla la perspectiva teórica del mismo, como una categoría de la clase principal que son los documentos audiovisuales.

Al observar y analizar los noticieros producidos por las televisoras y que son puestos a disposición del público en la Web, se encuentra una diversidad de expresiones en las que la representación del contenido, para facilitar la búsqueda, recuperación y acceso, son un área de oportunidad en todas los casos estudiados.

Este comportamiento es una alerta para las televisiones mexicanas, ya que la visibilidad de sus contenidos podría verse reducida debido a la carencia de una estrategia de mayor impacto en la representación de sus contenidos, legible no sólo para los lectores, sino también para los principales motores de búsqueda en internet.

Resulta necesario precisar el concepto de noticiero televisivo ya que su divulgación en la Web está adquiriendo diversidad de manifestaciones como son el noticiero en versión completa o en fragmentos, en vivo o bajo demanda. Al contar con una conceptualización más precisa, se supone que habría una mejor organización y preservación (al interior de las televisiones) a la vez que se podría promover una cultura de consulta más uniforme entre la audiencia, resultado del uso del lenguaje para satisfacer la expectativa e interacción entre usuarios generales, investigadores y productores, con la finalidad de responder a los procesos de cognición entre emisor y receptor (Van-Dijk, 2000).

\section{El tratamiento documental del noticiero es crucial para fortalecer la calidad de la representación del contenido y asegurar la pertinencia del análisis del discurso para su organización, acceso y preservación}

El noticiero transmitido es el resultado final del proceso de producción audiovisual periodística y en la actualidad queda capturado o documentado en un soporte tangible o intangible, analógico o digital, susceptible de ser identificado, analizado, indizado, catalogado, conservado y preservado, para brindar acceso posterior a diversos tipos de usuarios.

El noticiero desempeña funciones relevantes para la sociedad como son la supervisión del entorno, correlación, transmisión de la cultura y entretenimiento. Para estudiar sus procesos de emisión, contexto, discurso, canales empleados, así como ciertos comportamientos y efectos en la audiencia, se requiere acceder al documento. De ahí que este abordaje y conocimiento ofrece una oportunidad para profundizar en su conceptualización y en el tratamiento documental.

El noticiero televisivo mueve a las audiencias, por lo tanto es básico caracterizarlo como discurso y como documento a investigar en tres dimensiones, desde:

- la bibliotecología y los estudios de la información;

- la documentación periodística;

- la documentación audiovisual televisiva.

\section{Bibliografía}

Agirreazaldegi-Berriozabal, Teresa (2007). “Claves y retos de la documentación digital en televisión". El profesional de la información, v. 16, n. 15, pp. 433-442.

http://eprints.rclis.org/11133

http://dx.doi.org/10.3145/epi.2007.sep.05

Bock, Mary-Angela (2011). "You really, truly, have to "be there": video journalism as a social and material construction". Journalism \& mass communication quarterly, v. 88, n. 4, pp. 705-718. 
Caldera-Serrano, Jorge; Arranz-Escacha, Pilar (2012). Documentación audiovisual en televisión. Barcelona: Editorial UOC. ISBN: 9788490299821

Caldera-Serrano, Jorge; Benítez-Jaramillo, Blas (2005). “Estrategias de investigación en materia de archivos audiovisuales y televisivos". Scire: representación y organización del conocimiento, v. 11. n. 2, pp. 153-164.

http://www.ibersid.eu/ojs/index.php/scire/article/ view/1527

Condor, Susan; Antaki, Charles (2000). “Cognición social y discurso". En: Van-Dijk, Teun A. (compilador). El discurso como estructura y proceso. Barcelona: Gedisa, pp. 453-489. http://padron.entretemas.com/cursos/AdelD/unidad3/12C ognicionSociaDiscurso.pdf

Chacón-Gutiérrez, Inmaculada (1999). "Tipología y fiabilidad de las fuentes documentales". En: García-Gutiérrez, Antonio (ed.). Introducción a la documentación informativa y periodística. Sevilla: Editorial MAD, pp. 63-86. ISBN: 8483114607

Conesa-Santamaría, Alicia (1995). "La documentación en los medios de comunicación audiovisuales". En: FuentesPujol, M. Eulàlia. Manual de documentación periodística. Madrid: Editorial Síntesis, pp. 148-159. ISBN: 8477383049

Cox, Mike; Tadic, Linda; Mulder, Ellen (2006). Descriptive metadata for television. Burlington: Elsevier. ISBN: 978 0240807300

Cummins, R. Glenn; Chambers, Todd (2011). "How production value impacts perceived technical quality, credibility and economic value of video news". Journalism \& mass communication quarterly, v. 88, n. 4, pp. 737-752.

Curran, James (1990). "The new revisionism in mass communication research: a reappraisal". European journal of communication, June, v. 5, n. 2-3, pp. 135-164. http://dx.doi.org/10.1177/0267323190005002002

Den-Kamp, Claudy (2011). "Reimagining the archive: remapping and remixing traditional models in the digital era". Moving image, v. 11, n. 2, pp. 133-136.

Edmonson, Ray (2008). Filosofía y principios de los archivos audiovisuales. México: Fonoteca Nacional.

Gil-Leiva, Isidoro (2008). Manual de indización. Teoría y práctica. España: Ediciones Trea. ISBN: 9788497043670

González-Gozalo, Alfonso (2001). "La noción de obra audiovisual en el derecho de autor". Revista de propiedad intelectual, enero-abril, n. 7, pp. 9-74.

http://www.uclm.es/postgrado.derecho/_02/web/materiales/civil/Nocionobraaudiovisual.pdf

González-Quesada, Alfons (1995). “La evolución histórica de la documentación periodística". En: Fuentes-Pujol, M. Eulàlia. Manual de documentación periodística. Madrid: Editorial Síntesis, pp. 23-39. ISBN: 8477383049

Jara-Elías, Rubén; Garnica-Andrade, Alejandro (2007). ¿Cómo la ves? La televisión mexicana y su público. México: Ibope AGB. ISBN: 9789689282006
Lasswell, Harold D. (1948). "The structure and function of communication in society". En: Bryson, Lyman (ed.). The communication of ideas. A series of addresses. New York: Institute for Religious and Social Studies, 1948, pp. 37-51. http://www.dhpescu.org/media/elip/The\%20structure\%20 and\%20function\%20of.pdf

Ley Federal de Radio y Televisión (1960). Gobierno de los Estados Unidos Mexicanos.

http://www.diputados.gob.mx/LeyesBiblio/pdf/114.pdf

Ley Federal del Derecho de Autor (1996). Gobierno de los Estados Unidos Mexicanos.

http://www.cerlalc.org/derechoenlinea/dar/leyes_reglamentos/Mexico/Ley_Federal.htm

Naumis-Peña, Catalina. (2003) "Tesauro documental para la representación de contenidos educativos en videos". Investigación bibliotecológica: archivonomía, bibliotecología e información, enero-junio, v. 17 n. 34. pp. 144-174.

http://www.journals.unam.mx/index.php/ibi/article/ view/4016

Rodríguez-Reséndiz, Perla-Oliva (2011). El archivo sonoro. Fundamentos para la creación de una Fonoteca Nacional. Universidad Complutense de Madrid. Tesis doctoral. ISBN: 9788469507643

http://eprints.ucm.es/13738/1/T33255.pdf

Sabido, Miguel (2002). El tono. Andanzas teóricas, aventuras prácticas, el entretenimiento con beneficio social. México: UNAM. ISBN: 9683690866

Sánchez-Ruiz, Enrique E. (1989). “La investigación sobre televisión en México 1960-1988. Un acercamiento descriptivo". Comunicación y sociedad, n. 6, pp. 51-99.

http://www.publicaciones.cucsh.udg.mx/pperiod/comsoc/ pdf/6_1989/51-99.pdf

Smith, Anthony (1995). Television: an international history. Oxford: Oxford University Press. ISBN: 9780198119999

Soto-Hernández, Silvano (2009). Tratamiento documental del video. Tesis para obtener el grado de maestría en Bibliotecología y Estudios de la Información. México.

Soto-Hernández, Silvano (2011). "La telenovela mexicana: una mirada desde la Bibliotecología”. En: Cueva, Álvaro; Estrada, Carla; Garnica, Alejandro; Jara, Rubén; López, Heriberto; Orozco, Guillermo; Soto, Silvano. Telenovelas en México. Nuestras íntimas extrañas. México: Grupo Delphi, pp. 223-248. ISBN: 9786079567903

Turner, James M.; Ide, Mary; Luckow, Randal; Orefice, Isabella (2005). "Improving access to audiovisual and multimedia materials: the moving image case study of InterPares2". En: IFLA Conf Procs, August, pp. 1-9.

http://archive.ifla.org/IV/ifla71/papers/133e-Turner.pdf

Van-Dijk, Teun A. (2000). La noticia como discurso. Comprensión, estructura y producción de la información. Barcelona: Ediciones Paidós Ibérica. ISBN: 8475096220 http://investigacionsocial.sociales.uba.ar/files/2013/03/ Van-Dijk-La-Noticia-como-Discurso.pdf 